\title{
Interação Empresários-Setor Público no Turismo: uma análise institucional e neocorporativista na cidade de Huelva (Espanha)
}

\author{
The Interaction Between Entrepreneurs and the Public Sector in Tourism: \\ an institutional neocorporatist analysis of Huelva City (Spain)
}

\section{La Interacción entre los Empresarios y el Sector Público en el Turismo: un análisis institucional neocorporativista en la ciudad de Huelva (España)}

\author{
Bruno Martins Augusto Gomes ${ }^{1}$ \\ Alfonso Vargas-Sánchez ${ }^{2}$ \\ Huáscar Fialho Pessali ${ }^{3}$
}

\begin{abstract}
Resumo: Nos estudos na área do turismo temas como planejamento, participação da comunidade, descrição e avaliação de políticas são importantes e amplamente discutidos. Contudo, tendo em vista tanto a relevância dos empresários para o turismo e quanto a respectiva participação do setor público na provisão de infraestrutura, no financiamento de empreendimentos e na defesa interesses da sociedade civil relacionados ao turismo, são necessárias pesquisas que avancem na compreensão da interação dos empresários com o setor público. Por isso este trabalho tem como objetivo analisar a interação entre empresários de turismo e setor público, a partir de um estudo na cidade de Huelva, Espanha, destino que se encontra em sua fase inicial de organização e com expressiva interação do setor público com os empresários. A partir de um referencial teórico relacionando neocorporativismo, governança colaborativa e institucionalismo às políticas públicas de turismo foi realizada a coleta de dados por meio de entrevistas com três dos principais representantes do setor público e com sete dos principais empresários da cidade. Após a análise dos dados por meio da Teoria Fundamentada constatou-se que empresários e setor público sabem de sua interpendência, de forma que o setor público busca minimizar sua racionalidade limitada frente às questões do mundo empresarial, enquanto os empresários predominantemente defendem junto ao setor público a promoção do destino e infraestrutura. Por fim, as variáveis trajetória, atuação das associações, expectativa, e interação interna (entre empresários e entre organizações do setor público) também foram identificadas como relevantes na compreensão da interação.
\end{abstract}

Palavras-chave: Turismo; Interação; Setor Público; Empresários.

Abstract: In tourism research topics such as planning, community participation, policy description and evaluation are important and widely discussed. However, considering the importance of entrepreneurs for tourism and its need for the public sector as a provider of infrastructure and financing as well as a mediator of conflicting interests of civil society interests, tourism research needs to advance in the understanding of the interaction between tourism

\footnotetext{
${ }^{1}$ Professor do Departamento de Turismo da Universidade Federal do Paraná. Doutorando em Políticas Públicas na Universidade Federal do Paraná. E-mail: gomesbma@ufpr.br

2 Professor Catedrático de Organização de Empresas da Universidad de Huelva (Espanha). Doutor em Ciências Econômicas e Empresariais na Universidad de Sevilla (Espanha). E-mail: vargas@uhu.es

${ }^{3}$ Professor do Departamento de Economia e dos Programas de Pós-graduação em Políticas Públicas e em Ciência Política da Universidade Federal do Paraná. Doutor em Economia pela University of Hertfordshire (Inglaterra). Email: pessali@ufpr.br
} 
entrepreneurs and public sector. This study analyzes the interaction between tourism entrepreneurs and the public sector in the tourism public policies, studying the city of Huelva, Spain, which is in early stages of tourism organization and with significant public sector interaction with entrepreneurs. From a theoretical framework linking neocorporatism, collaborative governance and institutionalism with public policies tourism, we ran interviews with three leading public sector representatives and seven leading entrepreneurs of the cit. Analysis through Grounded Theory showed that entrepreneurs and public sector recognized their mutual dependence. The public sector strives to minimize the costs of its bounded rationality about business issues, while entrepreneurs strive to increase destination promotion and infrastructure. Finally, the variables path dependence, activities of entrepreneur's associations, beliefs, and internal interaction (between entrepreneur and between public sector organizations) also emerged as relevant in the interaction between tourism entrepreneurs and the public sector.

Keywords: Tourism; Interaction; Public Sector; Entrepreneurs.

Resumen: En los estudios de turismo cuestiones tales como la planificación, la participación comunitaria, la descripción y evaluación de las políticas son importantes y ampliamente discutidas. Sin embargo, teniendo en cuenta tanto la importancia de los emprendedores para el turismo y como la participación del sector público en la provisión de infraestructura, la financiación de proyectos y defensa de los intereses de la sociedad civil relacionadas con el turismo, es necesaria una investigación para avanzar en la comprensión de la interacción entre los emprendedores y el sector público. Así, este estudio tiene como objetivo analizar la interacción entre los empresarios turísticos y el sector público, a partir de un estudio en la ciudad de Huelva, España, un destino que se encuentra en sus primeras etapas de la organización y con una interacción significativa del sector público con las empresas. Desde un marco teórico en sobre neocorporativismo, gobernancia colaborativa y institucionalismo se realizó una recogida de datos a través de entrevistas con tres los principales representantes del sector público y siete de los empresarios de la ciudad. Después de analizar los datos utilizando la Teoría Fundamentada se encontró que los empresarios y el sector público conocen su independencia, por lo que el sector público busca minimizar sus problemas de racionalidad limitada sobre el mundo de los negocios y los empresarios se relacionan predominantemente con el sector público para promover el destino y las infraestructuras. Por último, las variables trayectoria, desempeño de las asociaciones, creencias y interacción interna (entre empresarios y entre las organizaciones del sector público) fueron también identificadas como relevantes en la comprensión de la interacción.

Palabras clave: Turismo; Interacción; Sector Público Empresarial.

\section{INTRODUÇÃO}

O turismo é um fenômeno social e tem a economia como parte essencial para a sua existência. Por isso vinculados a ele, além da sociedade civil do destino e dos turistas, estão o setor público e os empresários. Ainda que os turistas e a sociedade civil sejam importantes, estes se envolvem menos com as políticas públicas de turismo. Os turistas, por definição, permanecem no destino por um tempo limitado. Na sociedade civil, por sua vez, são poucos os que se dispõem a uma atuação cidadã nas políticas de turismo - ao contrário do que se vê nas políticas de saúde ou segurança. Os empresários de turismo, ao contrário, têm seu empreendimento diretamente vinculado às políticas públicas do setor e por isso é de se esperar que tenham uma relação mais próxima com o setor público. Da mesma forma, há uma expectativa de que o setor público se aproxime dos empresários obtendo assim mais informações e reduzindo a possibilidade de rejeição das políticas públicas, pois elas serão mais condizentes com as expectativas desta parte interessada.

Nos estudos na área do turismo temas como planejamento, participação da comunidade, 
descrição e avaliação de políticas são importantes e amplamente discutidos. Contudo, tendo em vista a relevância dos empresários para o turismo - pois é a partir deles que se tem um mercado turístico funcionando - e a respectiva necessidade do setor público como provedor de infraestrutura, de financiamento e de mediador dos interesses da sociedade civil relacionados ao turismo, são necessárias pesquisas que avancem na compreensão da interação empresários-setor público, inclusive com abordagens teóricas até então menos valorizadas.

Como a participação dos empresários nos fóruns de políticas públicas de turismo, na maioria das vezes se dá através da representação por suas associações, propõe-se a abordagem teórica do neocorporativismo para fundamentar a compreensão da interação empresários-setor público no turismo. Considera-se ainda que o funcionamento de um destino turístico é caracterizado pela interligação entre os agentes (principalmente hotéis, transporte, agências de receptivo e entretenimento) gerando efeitos econômicos, sociais, culturais e ambientais para as pessoas em seu entorno, tendo o setor público o papel de coordenar tais elos e mediar interesses da sociedade (Arruda et al., 2014; Zapata \& Hall, 2012). Por isso o conceito de governança colaborativa pode também ser útil à análise (Ansell \& Gash, 2008; Bruyn \& Alonso, 2012). O conceito complementa o neocorporativismo na medida em que abre espaço para considerar a participação das lideranças da comunidade e não somente as associações empresariais. Apesar de serem encontrados estudos que tratam de governança no turismo, o enfoque de governança colaborativa é menos frequente (Araújo \& Tapia, 1991; Schmitter, 1974). Por fim, temos por base uma abordagem institucional, pois a interação é fundamentada em hábitos ou modos instituídos de pensamento e ação (Hodgson, 2007; Mclennan, 2014).

Com esse aparato teórico, pretende-se então analisar a interação entre empresários e setor público nas políticas públicas de turismo a partir de um estudo na cidade de Huelva, Espanha. Huelva é a capital da província espanhola de mesmo nome, localizada ao sul do país em fronteira com Portugal. O turismo se desenvolveu na província com foco em sol e praia, e golfe. A partir do final da década de 90 essa experiência ajudou a expandir a percepção sobre um maior potencial da capital para o turismo, iniciando assim esforços públicos e privados para o turismo de compras, gastronômico, esportivo e de negócios.

Para tanto é preciso caracterizar o turismo na cidade de Huelva e os agentes envolvidos com as políticas públicas de turismo locais, identificar hábitos instituídos nas interações entre empresários e setor público, tentando dimensionar o impacto dessa interação sobre o turismo. Para isso será desenvolvido um aporte teórico capaz de sustentar o estudo da interação entre empresários e setor público envolvendo neocorporativismo, governança colaborativa e institucionalismo no turismo, o qual será tratado na próxima seção. Em seguida é exposta a metodologia da pesquisa, descrevendo-se a coleta de dados por meio de entrevistas e a análise a partir da Teoria Fundamentada. Segue então uma seção com os resultados da pesquisa e as considerações finais, reunindo as percepções construídas na pesquisa a respeito da interação empresários-setor público na cidade de Huelva. Espera-se ao fim poder tirar lições para a compreensão da organização do turismo em destinos emergentes e sobretudo de como seus 
agentes interagem.

\section{MARCO TEÓRICO}

\subsection{Neocorporativismo, Governança e Institucionalismo no Turismo}

De acordo com Schmitter (1974) quanto mais o Estado se torna necessário para garantir o capitalismo, mais ele precisa de conhecimento profissional e informação especializada, agregar opiniões e garantir legitimidade. Esse ciclo de dependência, segundo o referido autor, faz com que Estado e os empresários procurem um ao outro, gerando interações. No turismo esta dependência é aumentada pois o governo de um município, estado ou país que tem a intenção de estimular a atividade em seu território precisará do conhecimento dos empresários sobre o mercado e também do investimento dos mesmos em empreendimentos locais para receber o turista.

Hall (1999) destaca que a tendência contemporânea à privatização por parte do Estado também está presente no turismo. Por isso o modelo de setor público enquanto o responsável pela implementação de políticas foi alterado para um modelo corporativista que enfatiza a eficiência, relações entre as partes interessadas, papel do mercado e a presença marcante do interesse privado. Nesse ambiente, segundo o autor, há uma relação oscilatória em que ora os agentes do mercado desejam menos Estado (principalmente com menos regulação) ora desejam que o Estado se faça presente, principalmente financiando a promoção turística. Como resultado prático no turismo, segundo o referido autor, tem-se o planejamento do turismo perdendo importância enquanto ganham importância a publicidade, as redes e a governança.

Assim, acredita-se que a base para o entendimento da interação entre empresários e setor público no turismo tem uma base neocorporativista. Segundo Araújo e Tapia (1991), o neocorporativismo é um modelo institucionalizado de formação de políticas públicas no qual as associações empresariais colaboram entre si e com o Estado na articulação dos interesses e na implementação das políticas públicas. Nele a representação é caracterizada pela competição limitada entre um pequeno número de organizações centralizadas com o monopólio da representação, e não pela livre disputa entre grupos por recursos de poder dispersos na sociedade (Araújo \& Tapia, 1991). Ao assumir este entendimento de corporativismo relacionado às associações empresariais (denominado neocorporativismo ou corporativismo societal) descarta-se a aproximação do termo com aquele referente a regimes autoritários (corporativismo estatal).

O neocorporativismo também dá destaque aos conselhos de políticas públicas enquanto fóruns institucionalizados, regulados, compostos por representantes (não funcionam por democracia direta) de grupos de interesses específicos. Suas agendas são influenciadas pela dinâmica da área de política pública com a qual se relacionam (Cortes \& Gugliano, 2010).

Zapata e Hall (2012), citando o exemplo da Espanha, acrescentam que a evolução dos modelos de parceria público privada no turismo são influenciados por aquilo que ocorre na política e nas esferas governamentais superiores. Estes modelos se disseminaram após a 
restauração da democracia e seguiram a tendência à descentralização, à mercantilização das funções públicas, aos cortes financeiros, e à falta de recursos locais para implementação de políticas, o que resultou em novas formas de governança. Porém, segundo os autores, no turismo o setor público busca um balanço entre ser legítimo e ser competitivo e eficaz, a partir da estratégia de se voltar um pouco mais para o privado, sem alterar demasiadamente sua natureza.

Hall (1999) enfatiza ainda que o caráter difuso do turismo, enquanto um fenômeno que envolve economia e sociedade, produz um desafio particular para o setor público. Ele tem que estimular uma atividade com forte interesse empresarial mas que está estritamente relacionada com a cultura, os recursos naturais e o cotidiano de uma sociedade. O referido autor diz que a análise da interação entre os empresários e o setor público no turismo deve observar se os resultados atendem ao interesse público e assim contribuem para a sustentabilidade ou se estão voltados apenas interesses dos empresários.

A partir desta abordagem é possível avançar na análise da interação entre empresários de turismo e setor público adotando a proposta de Ansell e Gash (2008) sobre governança colaborativa. Para os autores a governança colaborativa é um arranjo governamental em que o setor público envolve diretamente agentes não-estatais na tomada de decisão relacionada a políticas públicas, sendo este arranjo formal, orientado para o consenso e deliberativo.

Na proposta de governança colaborativa de Ansell e Gash (2008) a autoridade final pode estar com o setor público, mas as partes interessadas terão responsabilidade com os resultados das políticas já que estarão diretamente envolvidos na tomada de decisão. E estes autores se referem a este envolvimento como formal, ou seja, há uma estratégia explícita do setor público para formalizar esta influência, que são os fóruns de políticas públicas, defendidos pelo neocorporativismo, conforme exposto. No turismo, abordagens voltadas para a coordenação, como defendido por Arruda et al. (2014), são importantes para a redução dos custos de transação e a consequente eficiência dos sistemas turísticos, em função da competição entre destinos, do uso de bens públicos como atrativos turísticos e da diversidade de possibilidades que podem ser ofertas ao turista. Todavia, como ressaltado por Bruyn e Alonso (2012) há uma dificuldade gerada pelo fato das decisões serem com frequência tomadas em função de interesses políticos e não em função do desenvolvimento do turismo em si. A isso se somam as interrupções e alterações não raro trazidas pela eleição de novos governantes.

Bruyn e Alonso (2012) esclarecem também que no turismo não há um modelo único de governança aplicável a qualquer destino turístico. As governanças desenvolverão, segundo os autores, atividades de planejamento, investimento e organização e/ou promoção do destino. A atuação de seus agentes no seu funcionamento dependerá da importância do turismo na economia local, do número de habitantes dos municípios, da forma de gestão, orçamento e credibilidade do órgão de turismo, do número, poder e interesse dos agentes ligados ao turismo, dentre outros elementos. Entende-se assim que a governança colaborativa amplia a abordagem corporativista, pois a interação pode ocorrer não apenas com a participação dos empresários e suas associações, mas com a presença dos representantes da sociedade civil. 
Entendido que a presença dos empresários é importante na construção e implantação das políticas de turismo e que o setor público tem papel relevante na coordenação destas, devendo zelar também pela participação e interesses da sociedade civil, é necessário compreender como ocorre esta interação entre os agentes no turismo. O institucionalismo fornece uma base sólida para esta análise, pois permite uma análise a partir dos hábitos de pensamento e ação presentes nesta interação, entendendo, conforme proposto por Hodgson (1988), que estes hábitos quando aceitos e praticados pelos agentes de um grupo constituem instituições (Hodgson, 1988).

Hodgson (2007) compreende que os hábitos são formados pela repetição de pensamento ou ação e quando compartilhados constituirão as instituições. Hodgson (2003) defende como relevantes as pesquisas que aprimoram o entendimento dos hábitos na vida econômica, em especial sob a ótica institucional. Ele propõe que estas investigações não se limitem à discussão teórica, diante da importância de abordagens empíricas analisando culturas, circunstâncias e casos. Assim, neste trabalho o conceito de instituição adotado segue estes entendimentos de Hodgson, ou seja, de que as instituições podem ser compreendidas como normas, regras, organizações ou hábitos coletivos de pensamento e ação estabelecidos ao longo do tempo.

Douglass North (1994) salienta que as instituições criam ordem, reduzem a incerteza, limitam escolhas e reduzem custos de transação. No campo da organização socioeconômica, Oliver Williamson (1989) traz variáveis que auxiliam no estudo destes hábitos coletivos de pensamento e ação dos agentes por meio da Economia dos Custos de Transação (ECT). Na ECT, a racionalidade limitada, a frequência, a incerteza, o oportunismo, os investimentos específicos condicionam o comportamento dos agentes e os consequentes custos de transação gerados, ou seja, os dispêndios necessários para garantir que uma transação ocorra conforme planejado. A racionalidade limitada conceitua a incapacidade do agente de conhecer perfeitamente todas as alternativas, conjuga-las e perceber suas conseqüências numa tomada de decisão (Simon, 1979). O oportunismo é aqui tratado como a busca pelos interesses próprios com dolo (Williamson, 1989). A frequência das transações dimensiona a troca de informação entre eles, reduzindo ou ampliando os problemas derivados de sua racionalidade limitada e do oportunismo. Cabe destacar que a incerteza dos agentes acerca do ambiente externo (insegurança sobre o futuro ou a ocorrência de fatos novos) podem levar os agentes a tomarem decisões diferentes do planejado. $\mathrm{E}$ a presença de investimentos específicos constrange o comportamento oportunista, ao demandar uma governança mais precavida (e custosa). Para mais detalhes sobre a aplicação da Economia dos Custos de Transação ao turismo é encontrada em Buckley (1987), Gomes (2008) e Rawlence (2010).

Ansell e Gash (2008) abordam a influência das interações passadas na instituição da colaboração, ressaltando que agentes envolvidos em conflitos resultantes em inimizades têm maior dificuldade de colaborar. Segundo estes autores, um histórico de conflitos intensos, ainda que não os tornem inimigos, pode instituir rancor, desconfiança, estratégias de manipulação e comunicações desonestas. Como exposto pelos autores, porém, um grau moderado de conflito pode não afetar a colaboração já que muitas vezes os agentes percebem que ela é a única forma 
de alcançar seus objetivos. E um histórico de cooperação, de acordo com Axelrod (1986), dependerá da importância dada ao futuro pelos agentes e das recompensas que vislumbram receber. Ansell e Gash (2008) enfatizam ainda que os agentes tendem a uma baixa participação quando percebem que podem alcançar as metas sozinhos, ou em grupos menores separados da governança.

Konrad (2006) lembra que os agentes são guiados por suas expectativas individuais que, num processo consciente, se ajustam às expectativas de outros ou coletivas. As instituições por sua vez geram entre os agentes uma expectativa em relação aos comportamentos dos demais, o que os estimula à uma certa maneira de agir e os capacita para contruir soluções razoáveis a um certo coletivo. Schneider e Ingram (2007) acrescentam que não basta identificar as ideias isoladamente e sua respectiva frequência de aparecimento entre os mesmos. Como as instituições estão em um contexto de agentes conectados, para identificá-las é necessário mapear estes agentes e então identificar o modo como eles compreendem a realidade, ou seja, os modos de compreensão, a maneira como interpretam os elementos de um espaço político (agentes, regras, idéias, interesses, e suas relações causais) e como os relacionam. Isto auxilia na explicação de quando e por quê ocorre a interação, o diálogo e a troca de experiência entre os agentes, bem como na identificação das raízes dos conflitos e das dificuldades na formulação de políticas públicas.

Zapata e Hall (2012) ressaltam, contudo, que a parceria público privada se institucionalizou como um mito racional para a gestão de destino turístico. Assim, os agentes defendem o mito da participação e da colaboração para obterem legitimidade e com isso acessarem recursos e benefícios. Mas na verdade são recorrentes a não participação, o não funcionamento de fóruns participativos, e a confissão velada de que isso é perda de tempo.

Diante do exposto, a Figura 1 sintetiza as variáveis apresentadas como explicativas dos hábitos coletivos de pensamento e ação presentes na interação empresários-setor público. Estas variáveis provêm da articulação entre as três abordagens teóricas (Institucionalismo, Governança Colaborativa e Neocorporativismo), e relacionadas com o turismo. Cada modo de compreensão obtido na coleta de dados poderá envolver mais de uma variável. 
Figura 1 - Variáveis para análise da interação empresários-setor público no turismo

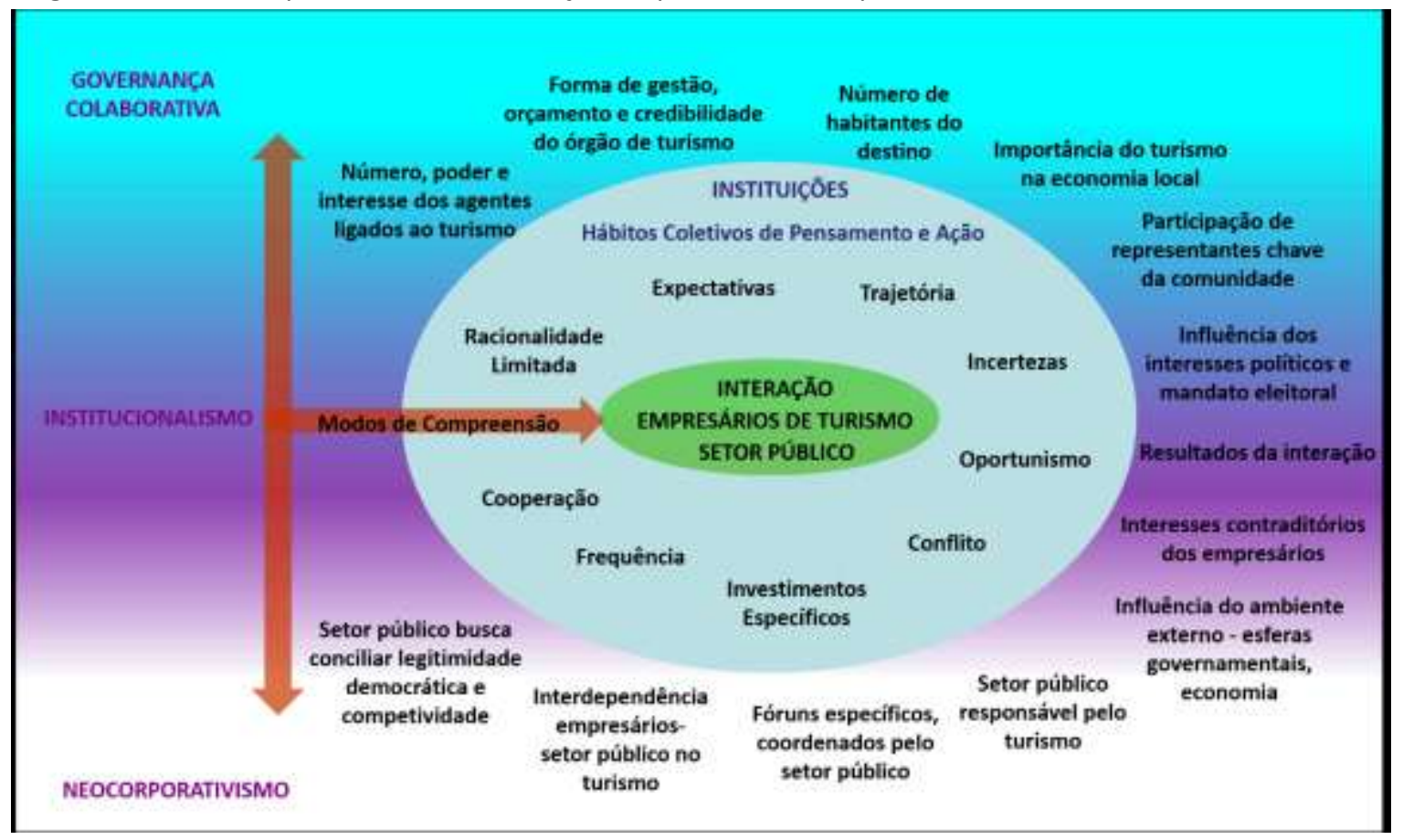

Fonte: Elaborada pelos autores

\section{METODOLOGIA}

Reconhecendo que as políticas públicas de turismo requerem a interação empresáriossetor público e que o neocorporativismo, a governança colaborativa e o institucionalismo são capazes de abordar a interação entre empresários-setor público nas políticas públicas de turismo, formulamos as seguintes perguntas para orientar nossa investigação: quais as características do turismo na cidade de Huelva? Como analisar a interação dos empresários com o setor público nas políticas públicas de turismo? Quais os hábitos dos empresários e do setor público ao interagirem? Quais as consequências desta interação para o turismo?

Diante do problema e dos objetivos desta pesquisa, optou-se por desenvolvê-la de maneira qualitativa, pois se busca investigar a percepção dos atores na interação entre empresários e setor público nas políticas públicas de turismo. Assim, foi realizado um estudo na cidade de Huelva sobre a interação entre empresários de turismo e setor público com dados coletados através de entrevistas. Foram realizadas dez entrevistas - três delas com lideranças do setor público envolvidas nas políticas de turismo e sete delas com empresários, incluindo uma importante entidade representativa dos empresários, gerentes de hotel, restaurantes, agências de emissivo e de receptivo da cidade de Huelva. Foram priorizados os de maior destaque e com disponibilidade em receber o entrevistador. Estas entrevistas se pautaram em um roteiro elaborado a partir do referencial teórico exposto.

Para a análise dos dados foram adotados os procedimentos da teoria fundamentada expostos por Charmaz (2009). A opção pela teoria fundamenta possibilita a construção de 
conceitos a partir de dados empíricos, o que facilita o diálogo científico e o progresso na pesquisa em turismo. Como observam Timmermans e Tavory (2010) a teoria fundamentada foi criada em reação à debilidade de pesquisas qualitativas as quais faziam ótimas descrições mas acrescentavam poucos pontos teóricos relevantes.

Assim, primeiramente foi criada uma legenda de identificação dos entrevistados visando manter o anonimato dos mesmos quando da interpretação dos dados. Então as entrevistas foram transcritas, formando a base textual de dados. Elas foram em seguida codificadas de acordo com o referencial teórico e analisadas utilizando os softwares Atlas Ti, UCINET e o endereço eletrônico $<$ http://worditout.com>, que elabora nuvens de palavras a partir de sua frequência individual e das associações entre elas.

Após esta etapa foram criados arquivos individuais para cada variável da pesquisa nos quais foram inseridas as frases dos entrevistados relacionadas à variável. Em seguida o arquivo referente a cada variável foi analisado considerando a frequência dos temas. Aqueles que mais vezes foram mencionados e os julgados relevantes a partir da impressão passada ao entrevistador foram selecionados, resultando numa síntese. À síntese foram acrescentados os memorandos com as anotações do entrevistador. Então, os conteúdos destes arquivos com as variáveis foram reunidos em grupos de acordo com os objetivos específicos da pesquisa e relacionados visando a construção de um texto único. Este texto único contém conceitos que respondem aos propósitos estabelecidos e construídos a partir das falas dos entrevistados, expostos nas seções do capítulo de resultados a seguir.

\section{RESULTADOS}

\subsection{Turismo em Huelva}

A província de Huelva, cuja capital tem o mesmo nome, está localizada na Andaluzia, no litoral sudoeste da Espanha, fazendo fronteira com Portugal. Sua história econômica é relacionada à agricultura e à mineração a partir do XIX, com forte presença de ingleses, ao que se somou nos anos de 1960 e 70 um polo industrial químico. Como exposto por Sánchez (2013) a província de Huelva possui um turismo de sol e praia forte, além de outros em crescimento. Na capital por sua vez o turismo está na fase inicial de desenvolvimento. A partir do final da década de 1990 começa a ganhar força uma visão mais positiva sobre as potencialidades da cidade para o turismo, percebendo-se a possibilidade de trazer o turista que já visitava as praias da província para conhecer a capital.

A percepção do turismo como atividade econômica relevante para a cidade de Huelva teve origem nos empresários. A resposta do setor público foi realizar uma série de transformações no espaço urbano, tornando-o mais atraente para o turismo e principalmente atuando para resgatar a autoestima da população local, valorizando sua história e seu patrimônio natural e cultural. Na cultura local era presente o pessimismo sobre o progresso da cidade em função dos poucos 
avanços trazidos pela mineração e pela indústria.

No ambiente urbano foram abertas novas avenidas, ruas tiveram sua urbanização melhorada, foram criados parques e construídos monumentos. Como destaque está o projeto urbanístico do Ensanche Sur, no qual se criou uma nova área de expansão imobiliária direcionada para a abertura de restaurantes, museus e uma marina, tendo como primeira obra a construção do novo estádio de futebol do Clube Recreativo de Huelva, o mais antigo time de futebol da Espanha. O clube, que estava em dificuldades financeiras, foi comprado pelo governo municipal e, com novos investimentos, chegou à primeira divisão do futebol espanhol. Isso divulgou a cidade de Huelva e contribuiu para melhorar a autoestima da população ao ver o time local competindo na sua própria cidade com grandes clubes como Real Madrid e Barcelona.

Outro esforço para tornar a capital um destino turístico é o projeto para a implantação de um roteiro turístico pelo rio Tinto, que é um diferencial de Huelva, a ser trabalhado a partir da recuperação da região de La Ría. Nos anos 2000 foi elaborado o Plano Estratégico de Turismo da cidade de Huelva, a partir do qual são eleitas ações prioritárias a serem executadas envolvendo o governo municipal, empresários e o governo regional (Junta de Andaluzia). O município formatou ainda novos roteiros pela cidade valorizando locais relevantes, como a Praça de Touros, além de se esforçar para converter o mercado municipal de simples local de venda de pescado e fruta em um atrativo turístico.

A partir da junção entre empresários com espírito empreendedor e o interesse do setor público, uma iniciativa de destaque para o turismo na cidade de Huelva foi o tema da gastronomia. Esta articulação buscou agregar valor àquilo que compõe uma tradição cultural de Huelva, a boa alimentação, especialmente envolvendo o camarão e o jamón ibérico (presunto). Apesar da relação histórica com a alimentação e o sucesso na produção de camarão e jamón, que diferenciam Huelva dos outros destinos, esta temática até então pouco fora trabalhada turisticamente. Dentro desta iniciativa há o projeto Proboca, uma marca de qualidade envolvendo o governo do município e empresários locais, contendo diretrizes mínimas que os restaurantes devem cumprir. Esta marca uma tentativa inicial de dar projeção nacional à gastronomia da cidade, inserindo-a, por exemplo, no Saborea España.

Há também um esforço para fazer de Huelva um destino para turismo de compras voltado ao público da Andaluzia e do Algarve (Portugal). Para tanto, além de investimentos nas vias urbanas, houve a construção do shopping Holea, que possui lojas das grandes redes presentes em outros centros de compras do país.

A cidade conta com um porto comercial de carga e que também serve a cruzeiros, o que já despertou a atenção local. Outro segmento que começa a ter seu potencial reconhecido localmente é o turismo cultural. Este é promissor em função da relação de Huelva com o descobrimento da América, pela presença local da cultura inglesa, além do patrimônio arqueológico que a cidade possui. Há ainda mais segmentos com potencial para serem aproveitados pela cidade, tais como o turismo de eventos, que pode ser trabalhado no viés cultural a partir das temáticas da tourada e do cinema assim como os eventos técnico científicos, 
aproveitando a infraestrutura dos hotéis da cidade e do Palácio de Congressos.

Por fim, há desafios para o melhor posicionamento da cidade de Huelva como destino turístico. Dentre eles se destacam a debilidade da infraestrutura de transportes (principalmente a melhoria do acesso por trem até Sevilha), as diferenças político-partidárias entre o governo municipal e o provincial (e a consequente formação de um produto turístico integrado envolvendo capital e província) e a insuficiente cooperação entre os empresários do turismo local. Há ainda as limitações de recursos públicos em função da crise econômica e o baixo acúmulo de conhecimento sobre como trabalhar o turismo - observado, por exemplo, na dificuldade dos agentes locais para negociarem com os operadores de cruzeiro visando a comercialização de passeios em Huelva (e não em Sevilha) quando os navios atracam na cidade.

\subsection{Interação empresários-setor público no turismo: instituições e suas implicações}

Esta seção apresenta os resultados da pesquisa e, seguindo a teoria fundamentada, sistematiza estes em conceitos sobre a interação empresários-setor público no turismo que possivelmente se manifestem em outros destinos também. A interação entre empresários de turismo e setor público em Huelva se dá principalmente por meio reuniões esporádicas e fóruns criados para a discussão de temas específicos, tais como turismo gastronômico, planejamento estratégico, promoção do destino e sinalização turística, sem haver uma periodicidade fixa para os encontros. A partir das entrevistas feitas, são destacadas duas situações para contextualizar os discursos sobre a dinâmica dessa interação. A primeira é o recorrente esforço tanto do setor público quanto dos empresários em dizer que a relação entre eles é boa, ressaltando o planejamento do turismo como uma ação conjunta e derivada do plano de turismo local. Também está presente entre eles a menção de que suas interações buscam o consenso e o respeito às necessidades do outro. A segunda é o conjunto de entidades mais lembradas nas falas dos entrevistados, o que permite elaborar a Figura 2.

Nela estão os agentes mais envolvidos com o turismo na cidade segundo o relato dos entrevistados. Na Figura a espessura da seta representa uma maior presença do agente nas falas. A parte do setor público mais mencionada pelos empresários é o governo provincial. $O$ agente privado com uma presença equilibrada entre os dois grupos (empresários e setor público) é a FOE (Federação Onubense de Empresários - onubense é o termo utilizado para se referir às pessoas naturais da cidade de Huelva) e suas associações. Destaca-se a presença dos restaurantes nas falas do setor público assim como o fato dos empresários serem mais mencionados pelo setor público que o contrário. $O$ sindicato não aparece nas falas do setor público assim como as autoridades portuárias e a universidade não são citadas entre os empresários. O trem (AVE/Renf), por sua vez, é um agente mencionado por ambos como necessário para o turismo na cidade de Huelva. 
Figura 2 - Interação entre agentes no turismo em Huelva

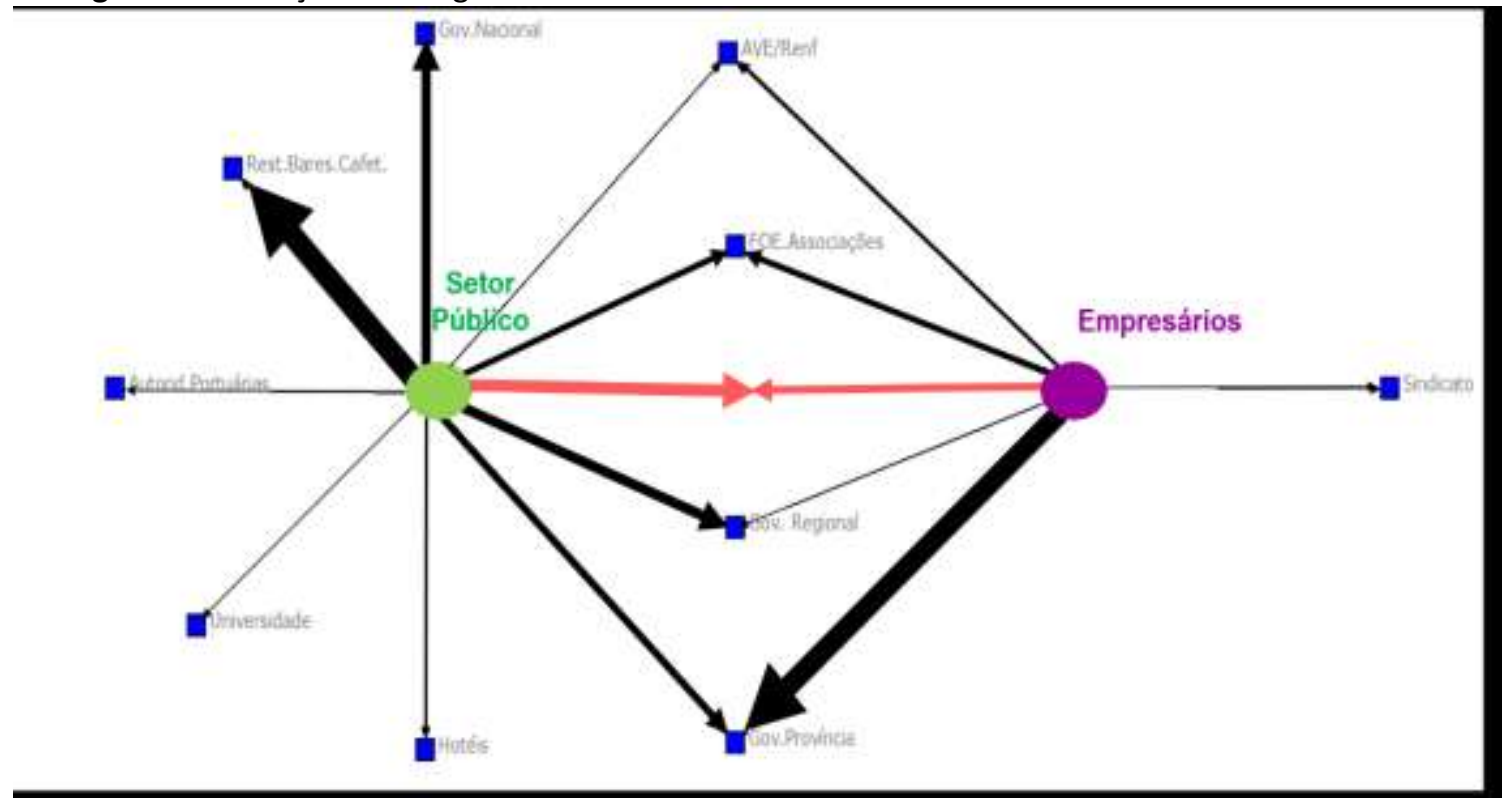

Fonte: Elaborado pelos autores

Cabe observar, porém, que a fala sobre a boa relação entre o setor público e os empresários foi menos presente entre os empresários, sendo constatada uma desconfiança em relação às promessas do setor público. Há entre os empresários a ideia de que o setor público poderia se dedicar mais às questões do turismo. E ainda, para eles a tomada de decisão é instrumental por parte dos políticos, ou seja, para decidirem por se envolverem em uma iniciativa tem grande peso a visibilidade que esta Ihes proporcionará. Destaca-se ainda entre ambos agentes a menção do planejamento do turismo ao ressaltarem que as ações devem ser conjuntas e seguindo o plano de turismo local.

O setor público evidencia seu conhecimento sobre a importância da participação da sociedade e sobretudo dos empresários na elaboração e execução do plano de turismo. Assim, está presente no setor público uma busca por conciliar legitimidade democrática e competividade do turismo. Enquanto propulsor do turismo local, ele atua organizando o espaço urbano, atendendo as demandas da comunidade, mas também, ampliando a disponibilidade de áreas para investimento privado.

O empresário de turismo para sobreviver requer a presença de turistas, mas as campanhas promocionais, têm um custo elevado, sobretudo para público internacional. Assim a atuação do setor público para atender os empresários também se dá na promoção. Porém esta iniciativa requer a interação com os empresários tendo em vista a racionalidade limitada do setor público em relação à promoção de um destino, especialmente sobre qual tipo de turista tem mais interesse no destino, algo que os empresários conhecem melhor.

A intensidade da interação também é afetada pelas crenças dos agentes de maneira que para alguns empresários cada um deve atuar por si, sem envolvimento com o setor público. Esta 
visão é mais presente nas empresas menores, com menos empregados e uma preocupação mais voltada para o curto prazo. No caso dos agentes políticos, o caráter mais ou menos empreendedor e centralizador daquele que está à frente do setor público assim como suas ideologias políticas influenciarão a interação. E a expectativa dos empresários que acreditam na interação é de que tenham oportunidade para expor e terem acatadas suas demandas, pois entendem que são as pessoas mais apropriadas para o desenvolver o turismo do local.

A trajetória afeta as interações do presente em função do aprendizado gerado pelas experiências passadas geram. Primeiramente os resultados de fracassos anteriores no planejamento do turismo ou na interação empresários-setor público tendem a economizar em custos de transação relativos à racionalidade limitada nas interações presentes já que os agentes conhecem melhor os resultados de determinadas tomadas de decisão. Segundo, repetidas decepções tendem a diminuir a expectativa dos agentes em relação à outra parte. $O$ atraso do setor público para pagar serviços contratados juntos aos empresários de turismo e a porcentagem de fracasso das solicitações apresentadas ao setor público, causada por interesses políticos ou limitação de financeira, desestimulam os agentes privados a se envolverem na interação. Terceiro, o histórico de atuação do setor público na organização da economia local tende a influenciar o entendimento do empresariado acerca de quem é responsável pelas atividades relativas a uma política de turismo local. Se historicamente a iniciativa para impulsionar o desenvolvimento do destino turístico foi do setor público haverá uma maior resistência inicial dos empresários por pensarem que este continua sendo dever do setor público. À medida em que os empresários têm a iniciativa de promover e evidenciar o potencial turístico local, o setor público, para se legitimar frente a este grupo, assume o discurso sobre a importância do turismo se vê gradativamente responsável por agir nas políticas públicas relacionadas à área. Esta situação também requererá dos empresários um esforço de persuasão para convencerem o setor público sobre as áreas que são mais importantes para sua atuação.

A iniciativa da interação por parte dos empresários também pode ocorrer na tentativa de minimizar os custos da racionalidade limitada do setor público frente às questões do mundo empresarial, que às vezes é agravada pelo longo tempo demandado pelos processos burocráticos. Esta situação pode levar o setor público a práticas em descompasso com as rápidas transformações do mercado, prejudicando assim o desempenho das empresas.

Assim, quando a iniciativa da interação parte dos empresários e não coincide com os objetivos dos agentes do setor público, estes últimos enquanto não percebem resultados concretos da mesma (por exemplo, aumento no número de turistas), tendem a ser mais cautelosos no envolvimento, de forma a minimizar os custos da racionalidade limitada dos empresários com relação às demais demandas da comunidade local. Cabe a observar que a existência de um projeto bem definido por parte dos empresários e o fato de serem reconhecidos fora do destino tendem a facilitar a adesão do setor público.

A interação entre os próprios empresários, quando caracterizada pela baixa cooperação, dificulta a interação destes com o setor público. Isto é mais presente entre empresas nas quais o 
planejamento estratégico e o longo prazo têm menor importância, características comuns em gestões não profissionais. A dificuldade é ampliada na ausência de um agente coordenador que atenue conflitos entre eles e construa propostas coletivas que possam ser levadas ao setor público. O contrário tende a acontecer em associações com maior número de associados ou que representam empresas de maior poder econômico. A maior atenção dada às ações de interesse comum e às propostas de impacto coletivo Ihes facilitam a aproximação com o setor público. As propostas mais próximas das políticas públicas definidas como prioritárias terão maior aceitação. No turismo em Huelva a interação com o setor público pelas associações ou suas federações é mais comum por parte dos empresários de hotelaria, gastronomia e turismo receptivo.

As interações podem ser regulares, ou seja, acontecem com uma frequência de encontros determinada e perene, estando mais relacionadas a questões recorrentes num destino turístico, como planejamento e organização do turismo. Nesta interação os empresários são mais heterogêneos, com o predomínio de empresas com menor capacidade financeira e que frequentemente participam para conhecerem as iniciativas do setor público e referendar as políticas públicas. Mas há interações mais específicas que surgem frente à junção de interesses de agentes políticos ou de empresários de destaque no mercado turístico, levando os dois grupos a uma interação intensa num período determinado e a uma clara definição de quem são os envolvidos. Nesta interação está presente um grupo menor de empresários, mas com capacidade para colaborar financeiramente com as propostas e com voz suficiente para mudar a tomada de decisão dos agentes políticos. Isso normalmente está associado a oportunidades de mercado identificadas por eles e que são então articuladas às políticas públicas.

Dentre os principais benefícios que estes grupos mais próximos ao setor público obtêm estão o acesso antecipado às ações que o setor público pretende desenvolver assim como a possível influência na aprovação de projetos de seu interesse. Esta interação frequentemente envolve investimentos específicos que favorecerão o coletivo (para garantirem a legitimidade do envolvimento do setor público) mas atenderão em grande medida os interesses dos agentes privados envolvidos. Estes investimentos específicos criam um maior comprometimento do setor público com o turismo, mas também abrem a possibilidade para o favorecimento de determinados empresários, como, por exemplo, o direcionamento de uma campanha publicitária do destino à um público-alvo muito específico.

$\mathrm{Na}$ interação empresários-setor público há um conflito de ideias sobre a relação entre demanda turística e oferta de serviços. Enquanto os empresários pensam que cabe ao setor público oferecer infraestrutura sobretudo de transporte para que assim o turista possa visitar o destino, o setor público defende que é pelo incremento do número de turistas que é possível justificar investimentos públicos ou atrair empresas para ofertarem tais serviços. Existe ainda um conflito relacionado à tentativa do setor público em ampliar o número de empresas envolvidas (para garantir sua legitimidade tendo em vista no aspecto democrático). Esta ampliação muitas vezes desagrada os empresários já que a eficiência em termos de mercado turístico requer o envolvimento não de todas, mas das empresas especializadas e mais fortes na área. 
O êxito da interação também está vinculado à relação intragovernamental. Um exemplo é que o funcionamento de um destino requer, além do órgão de turismo, a atuação de outros como limpeza urbana, saneamento, segurança e trânsito. O melhor diálogo entre estes órgãos melhora o nível de informação e tende a facilitar a implementação das propostas, gerando assim mais interesse dos empresários em interagir. A baixa coordenação intragovernamental afeta a interação deste agente com os empresários na medida em que abre a possibilidade para ações redundantes que podem desperdiçar recursos e comprometer os resultados de uma política pública de turismo. Por exemplo, se a promoção de uma região turística é feita envolvendo as diferentes esferas governamentais (município e província) tem-se a criação de uma referência mais forte, permitindo uma melhor ação promocional em função da união de recursos e melhorando assim a comunicação com o turista, que, por meio de um único contato, passa a ter conhecimento dos diferentes atrativos da região. Outro exemplo é a divergência de interesses políticos, principalmente derivados de diferenças partidárias as quais geram restrições orçamentárias que interferem no atendimento de uma demanda apresentada pelos empresários. Quando estes conflitos são menores em função das relações intragovernamentais, o setor público tem a capacidade de agir como o gestor de interesses acolhendo as demandas dos empresários e levando-as às outras esferas de governo.

$\mathrm{Na}$ interação empresários-setor público a estrutura formal tem um papel importante. Primeiramente a existência de um órgão oficial de turismo traz mais confiança para os empresários sobre o comprometimento do setor público. Além de um órgão oficial de turismo a existência de um fórum específico para a interação possibilita uma maior transparência assim como uma maior regularidade nos encontros entre empresários e setor público. Dentre estes fóruns estão os conselhos de turismo e as mesas ou câmaras temáticas, que diferente dos primeiros, se dedicam a temas mais específicos do turismo e se reúnem sem periodicidade fixa.

O grau de profissionalização do turismo nesta estrutura formal e a vulnerabilidade destes profissionais com as alterações do mandato eleitoral afetam a interação, pois o conhecimento técnico sobre turismo, sob menor influência política, facilita o entendimento das demandas empresariais por parte do setor público. Isso é comprometido quando a equipe de profissionais de turismo não tem estabilidade e a cada nova eleição os empresários precisam iniciar um novo esforço na construção de um entendimento com os novos profissionais nomeados pelo agente político empossado.

Estas alterações ocorridas em função do mandato eleitoral trazem incertezas para os empresários sobre os novos rumos da política pública, gerando desinteresse dos mesmos em iniciar mais uma vez a construção de uma interação duradoura para a formulação e implementação de políticas públicas. Como a manutenção do político no cargo depende de votos, a expectativa gerada pelas eleições estimula setor público e empresários a se aproximarem visando votos ou a adoção/manutenção de políticas públicas. Os compromissos assumidos no período eleitoral afetarão a interação ao longo do mandato.

Assim, cabe destacar as percepções do setor público e dos empresários de turismo, suas 
similaridades e distinções. Empresários e setor público reconhecem e ressaltam a importância da interação entre eles, porém observam que as diferenças nas dinâmicas de funcionamento de cada um (público e privado) afetam esta interação. Sobre a cooperação, tanto o setor público quanto a iniciativa privada a associam à necessidade de um planejamento estratégico, à capacidade dos empresários para se envolverem em empreendimentos conjuntos com o setor público, e à importância da coordenação entre os órgãos públicos ao lidarem com o turismo. A iniciativa privada enfatiza a necessidade de cooperação, enquanto ressalta a influência negativa da competição entre os próprios empresários do ramo.

A racionalidade limitada no setor público tem significância principalmente com relação ao nível de conhecimento (público e privado) sobre como trabalhar o turismo. Busca-se amenizar tal dificuldade com o envolvimento dos empresários e com a profissionalização de sua estrutura voltada ao turismo. Em relação à trajetória, setor público e iniciativa privada a relacionam a um histórico de importância do turismo na economia local e de compromisso do setor público com o mesmo.

Ambos relacionam a incerteza nas políticas públicas de turismo às diferenças partidárias (entre município e província) e principalmente à crise financeira que, segundo a iniciativa privada associa resultou em redução da demanda. O setor público manifesta uma expectativa relacionada à ampliação do turismo local principalmente por meio do fortalecimento de um novo segmento turístico, o da gastronomia. Mas entre os empresários predomina uma expectativa de aproximação das ações do setor público de suas demandas, dentre as quais se destacam a melhoria da infraestrutura de transporte e a promoção do destino.

Nessa mesma linha, em relação aos investimentos específicos o setor público realça seu papel como principal criador de atrativos e roteiros turísticos, porém os empresários enfatizam o fracasso de atrativos turísticos que, apesar do alto investimento público, não estimulam a economia local conforme almejado. Por isso é comum entre os empresários a defesa de aporte financeiro pelo setor público, mas direcionando apenas para atrativos e roteiros eleitos por eles a partir do conhecimento de mercado que possuem.

Na Figura 3 temos uma nuvem de palavras que ilustra as expressões (relativas às variáveis e relações estudadas) mais frequentes nas falas dos entrevistados. Isso ajuda a entender os hábitos de pensamento instituídos na interação entre empresários e setor público no turismo em Huelva. Na nuvem, o tamanho da fonte de cada palavra é proporcional à sua utilização. As expressões que mais se destacam são: interdependência empresários-setor público, cooperação, racionalidade limitada, governança e interação entre os empresários. Tiveram uma frequência intermediária as variáveis planejamento do turismo pelo setor público, ambiente externo, expectativa, trajetória, iniciativa, interesse dos políticos e mandato eleitoral, poder dos agentes de turismo (empresários) e interação pelas associações. E as variáveis de menor frequência para discutir a interação foram capacidade do órgão de turismo, fracasso, incerteza, oportunismo, conflito, frequência, consenso, investimentos específicos, interesse dos políticos pelo turismo e participação de representantes da comunidade. 
Figura 3 - Variáveis Explicativas Da Interação Empresários-Setor Público

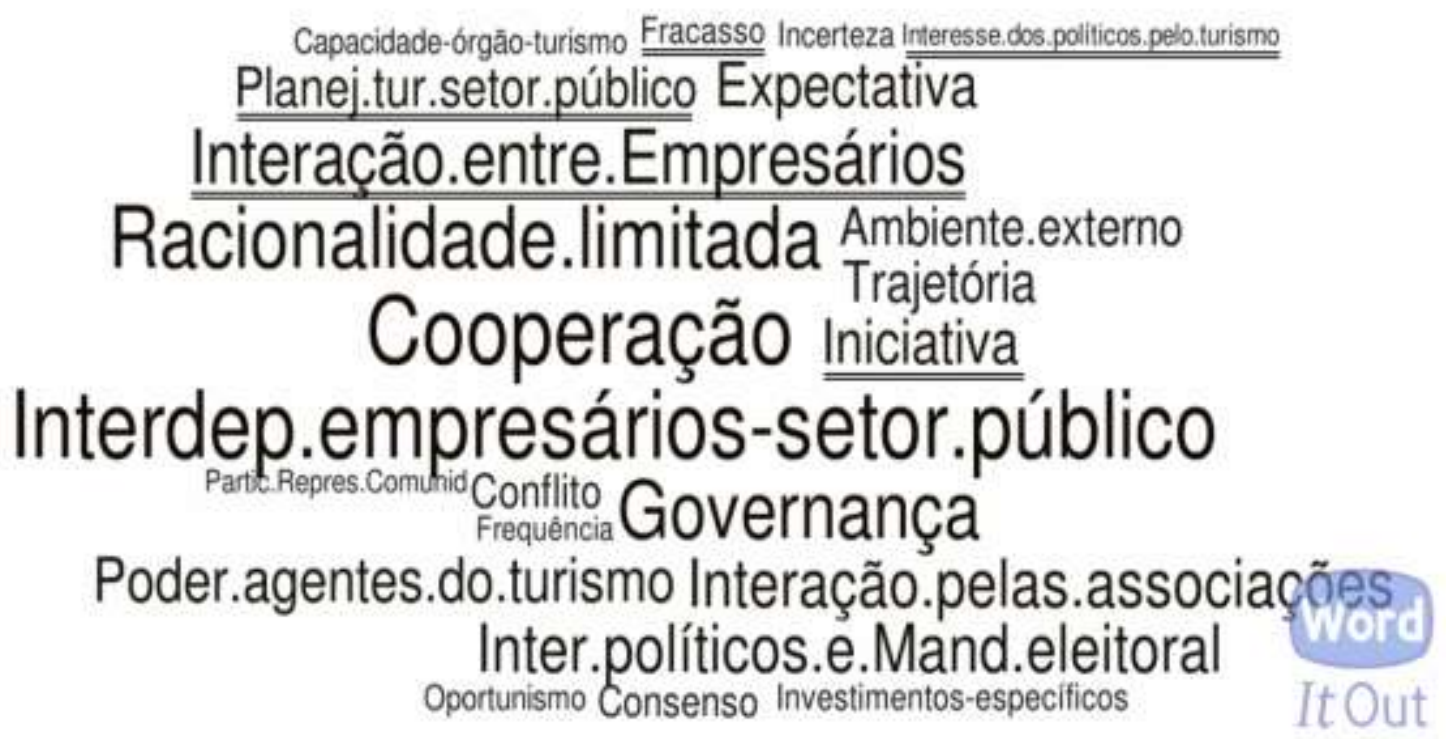

Fonte: Elaborado pelos autores

As variáveis "importância do turismo para a economia local" e "número de habitantes do destino" apesar de constarem na discussão teórica (Figura 1), neste estudo tiveram uma frequência de utilização baixa e por isso não constam na Figura 3. Já as variáveis grifadas na na figura - interação entre os empresários, quem toma a iniciativa da interação, planejamento do turismo pelo setor público, fracasso e interesse dos políticos pelo turismo - inicialmente não foram mencionadas no referencial teórico mas foram frequentes nas entrevistas, mostrando-se instituídas na interação empresários-setor público em Huelva.

\section{CONSIDERAÇÕES FINAIS}

No propósito de analisar a interação entre empresários e setor público nas políticas públicas de turismo a partir de um estudo na cidade de Huelva, Espanha, a articulação entre neocorporativismo, governança local e institucionalismo mostrou-se capaz de fornecer conceitos e variáveis robustos para explicar a interação entre empresários e setor público.

Schmitter (1974) expõe que quanto mais o Estado se torna necessário para garantir o capitalismo, mais ele precisa de conhecimento profissional e informação especializada. Essa afirmação se faz válida na cidade de Huelva por ser um destino turístico emergente. Nela a interação do setor público com os empresários é ainda mais importante em função do número reduzido destes no destino e pelo conhecimento específico que já acumularam sobre o setor.

O setor público mantém uma interação com os vários segmentos empresariais do turismo, mas no turismo gastronômico ocorrem interações mais intensas e com maiores resultados. Há que se destacar que Huelva já possuía tradição local na produção de camarão e jamón, já tendo originado chefs de renome a promover a tradição alimentar local relacionada àqueles produtos. 
Na interação, como expõe Araújo e Tapia (1991) a representação dos empresários é caracterizada pela competição limitada entre um pequeno número de organizações e não pela livre disputa entre grupos. Assim, as associações empresariais são importantes enquanto articuladoras das diferenças entre os empresários de turismo levando uma demanda mais forte e homogeneizada para o setor público, como a atuação da FOE, em Huelva.

O setor público atua no planejamento e execução das políticas de turismo buscando conciliar legitimidade democrática e competividade por meio de um discurso que atenda os diferentes interesses da sociedade civil e empresariais. Neste aspecto o peso do turismo no discurso tem relação com a importância da atividade para a economia local, inclusive numa perspectiva de futuro em se tratando de destinos com histórico agroindustrial.

Por meio das entrevistas, constatou-se que empresários e setor público sabem de sua interdependência. Sua interação ajuda a minimizar os problemas oriundos da racionalidade limitada, principalmente sua incapacidade de conhecer perfeitamente todas as alternativas de ação cabível a cada parte e entender suas consequências (Simon, 1979). Por um lado, o setor público busca reduzir os custos de sua racionalidade limitada frente às questões do mundo empresarial. E por outro, os custos da racionalidade limitada e do autointeresse com dolo dos empresários, que buscam de forma míope benefícios para seus negócios individuais, são em alguma medida controlados. Assim é possível alcançar demandas coletivas pela promoção do destino e por infraestrutura, externalidades positivas que trazem benefícios ao conjunto de atores e que transbordam a ação individual. Esta interpendência os leva a buscar o consenso diante de divergências, como por exemplo sobre o que deve vir primeiro - a oferta de infraestrutura ou o fluxo turístico - e por conseguinte sobre quem precisa agir em que momento para impulsionar o turismo local.

Observou-se que as políticas públicas tendem a ser direcionadas para áreas em que há um grupo de empresários com propósitos coincidentes com os interesses dos líderes do setor público e que estão dispostos a interagir. Como resultado, mesmo que a autoridade esteja com o setor público, mas as partes interessadas terão responsabilidade com os resultados das políticas já que estarão diretamente envolvidos na tomada de decisão (Ansell \& Gash, 2008).

Como Konrad (2006) ressalta, os agentes são guiados por suas expectativas individuais que, num processo consciente, se ajustam às expectativas de outros ou coletivas. Nesse sentido, as expectativas dos agentes afetam sua disposição a interagir. De fato, em Huelva alguns empresários mostraram interagir pouco por não acreditarem no setor público, enquanto o setor público manifestou menor disposição para atuar com empresários de turismo atuando em áreas que entende como não prioritária. Também pesou na expectativa dos empresários em relação ao setor público o tempo que este requer para honrar suas promessas, inclusive aquelas relacionadas ao pagamento a serviços prestados pelos empresários.

Ansell e Gash (2008) expõem que as interações passadas afetam a instituição da colaboração. Nesse sentido foi identificado que na interação são bem recebidos aqueles agentes com um histórico de sucesso no mercado nacional ou internacional. Já a trajetória do setor público 
é avaliada pelos empresários considerando o histórico de honrar com suas promessas, principalmente se ao longo dos anos de mandato o setor público concretizou seu discurso em prol do turismo com ações práticas.

Finalmente, a interação entre empresários e setor público é consequência dos hábitos de pensamento e ação entre os próprios empresários e entre os agentes do setor público. Pelo que se viu em Huelva, empresários mais articulados e com uma associação forte defenderão melhor seus interesses. Viu-se ainda que se requer do setor público uma coordenação intragovernamental. $\mathrm{Na}$ tentativa de lidar com esta questão, na experiência local, criou-se uma estrutura formal dedicada à atividade, que atua de forma planejada, por meio de profissionais com formação na área de turismo e estabilidade em suas carreiras. Esse desenho institucional visa reduzir a incerteza dos empresários, mas sem perder de vista o entendimento do turismo como um fenômeno que, além de efeitos econômicos, possui também implicações sociais, culturais e ambientais.

A evidente presença da interação entre empresários e o setor público no desenvolvimento do turismo traz novos elementos à ideia defendida por Zapata e Hall (2012) de que a parceria público privada se institucionalizou como um mito racional da gestão de destino turístico defendido pelos agentes para obterem legitimidade e acessarem benefícios. Sua presença nos destinos turísticos exige mais estudos específicos, que busquem entender o histórico de hábitos institucionalizados na região de interesse para identificar a relação entre as variáveis apresentadas e sua validade, inclusive em destinos mais maduros que a cidade de Huelva. As variáveis "importância do turismo para a economia local" e "número de habitantes do destino", por exemplo, pouco se destacaram neste estudo, mas é possível que o ciclo de vida dos destinos condicione a interação empresários-setor público, afetando seus hábitos coletivos de pensamento e ação. E se há suspeita de que isso faça sentido para um determinado caso, então cabe aos interessados em compreender melhor o turismo sob a ótica do institucionalismo investigar.

\section{AGRADECIMENTO}

Bruno Martins Augusto Gomes agradece a bolsa concedida pela Fundação Carolina Programa de Mobilidade de Professores e Investigadores Brasil-Espanha (2013/2014) que permitiu o estudo de campo. Huáscar Fialho Pessali agradece ao CNPq pelo apoio financeiro (Processo PQ 306568/2012-8).

\section{REFERÊNCIAS}

Arruda, D. O., Mariani, M.A.P., \& Caleman, S.M.Q. (2014). Coordinación y Estructuras de Gobernanza en un Sistema Productivo de Turismo. Estudios y Perspectivas en Turismo, 23(2), 343-361.

Ansell, C., \& Gash, A. (2008). Collaborative governance in theory and practice. Journal of Public Administration Research and Theory, 18(4), 543-571. 
Araújo, A. M. C., \& Tapia, J. R. B. (1991). Corporativismo e neocorporativismo: exame de duas trajetórias. BIB - Revista Brasileira de Informação Bibliográfica em Ciências Sociais, 2, 3-30.

Axelrod, R. (1986). La evolución de la cooperación: el dilema del prisionero y la teoria de juegos. Madrid: Alianza.

Bruyn, C., \& Alonso, A.F. (2012). Tourism Destination Governance: guidelines for implementation. In: FayosSolá, E., Silva, J.A.M., \& Jafari, J. (org.). Knowledge Management in Tourism: policy and governance applications. Bingley: Emerald.

Buckley, P.J. (1987). Tourism - an economic transactions analysis. Tourism Management, 8(3), 190-194

Charmaz K. (2009). A construção da teoria fundamentada: guia prático para análise qualitativa. Porto Alegre: Artmed.

Cortes, S.V., \& Gugliano, A. (2010). Entre neocorporativistas e deliberativos: uma interpretação sobre os paradigmas de análise dos fóruns participativos no Brasil. Sociologias, 12(24), 44-75.

David, P. (1985). Clio and the economics of QWERTY. The American Economic Review, 75(2), 332-337.

Gomes, B. M. A. (2008). Políticas Públicas e as Transações em Regiões Turísticas. São Paulo: All Print.

Hall, C.M. (1999). Rethinking Collaboration and Partnership: a public policy perspective. Journal of Sustainable Tourism, 7(3/4), 274-289.

Hodgson, G. M. (1988). Economics and institutions: a manifesto for a modern institutional economics. Oxford: Polity Press.

Hodgson, G.M. (2003). The hidden persuaders: institutions and individuals in economic theory. Cambridge Journal of Economics, 27, 159-175.

Hodgson, G.M. (2007). The Revival of Veblenian Institutional Economics. Journal of Economic Issues, 41(2), 325-340.

Jamal, T.B., \& Getz, D. (1995). Collaboration Theory and Community Tourism Planning. Annals of Tourism Research, 22(1), 186-204.

Konrad, K. (2006). The social dynamics of expectations: the interaction of collective and actor-specific expectations on electronic commerce and interactive television. Technology Analysis \& Strategic Management, 18(3/4), 429-444.

Mclennan, C.J., Ritchie, B.W., Ruhanen, L.M, \& Moyle, B.D. (2014). An institutional assessment of three local government-level tourism destinations at different stages of the transformation process. Tourism Management, 41(2), 107-118.

North, D. (1994). Custos de Transação, Instituições e Desempenho Econômico. Rio de Janeiro: Instituto Liberal.

Pessali, H. (2011). Public Policy Design in Developing Societies: beyond transplantation. Journal of 
Developing Societies, Monterey Bay 27(1), 11-28.

Rawlence, S. (2010). Integrating Transaction Cost and Institutional Theories in an Emerging Market Context: the case of the Tiger Leaping Gorge, Southwest China. Thesis (PhD). The University of Edinburgh.

Sánchez, A. V. (2013). El Turismo en la Provincia de Huelva. Huelva.

Schmitter, P.C. (1974). Still the Century of Corporatism? The Review of Politics, 36(1), 85-131.

Schneider, A, \& Ingram, H. (2007). Ways of Knowing: Implications for Public Policy. Annual Meeting of the American Political Science Association, Chicago.

Simon, H. (1979). Rational decision making in business organizations. American Economic Review, 69(4), 493-513.

Timmermans, S. \& Tavory, I. (2010). Advancing Ethnographic Research through Grounded Theory Practice. In: BRYANT, A.; CHARMAZ, K. The Sage Handbook of Grounded Theory. London: Sage Publications.

Zapata, M.J., \& Hall, C.M. (2012). Public-private collaboration in the tourism sector: balancing legitimacy and effectiveness in local tourism partnerships - The Spanish case. Journal of Policy Research in Tourism, Leisure and Events, 4(1), 61-83.

Williamson, O. E. (1989). Las Instituciones Económicas del Capitalismo. México: Fondo de Cultura Económica.

Artigo recebido em: 02/05/2014. Artigo aprovado em: 19/11/2014. 